\title{
Coupling the Short-Term Global Forecast System Weather Data with a Variable Source Area Hydrologic Model
}

Andrew R. Sommerlot ${ }^{1}$, Moges B. Wagena ${ }^{1}$, Daniel R. Fuka ${ }^{1}$ and Zachary M. Easton ${ }^{1 *}$

${ }^{1}$ Department of Biological Systems Engineering, Virginia Tech, Blacksburg, VA, USA

*Corresponding Author Email: zeaston@vt.edu

Keywords: Real-time Forecast, SWAT, Soil and Water Assessment Tool, Short-term Forecast, Distributed Hydrology, Non-point Source Pollution, Runoff Probability, Soil Moisture, High Performance Computing

10

\section{Abstract}

Few current modeling tools are designed to predict short-term, high-risk runoff from hydrologically sensitive areas (HSAs) in watersheds. This study couples the Soil and Water Assessment Tool-Variable Source Area model with the Climate Forecast System Reanalysis model and the Global Forecast System-Model Output Statistics model short term weather forecast, to develop a HSA prediction tool designed to assist producers, landowners, and planners in identifying high-risk areas generating storm runoff and pollution. Short-term predictions for stream flow and soil moisture level were estimated in the South Fork of the Shenandoah river watershed. Daily volumetric flow forecasts were found to be satisfactory four days into the future, and distributed model predictions accurately captured sub-field scale HSAs. The model has the potential to provide valuable forecasts that can be used to improve the effectiveness of agricultural management practices and reduce the risk of non-point source pollution.

\section{Introduction}

Non-point source (NPS) pollution is a leading cause of water quality impairment in the United States and a major component of this pollution is caused by runoff from agricultural lands (Shortle et al., 2012). During the last several decades numerous environmental standards and 
management practices (e.g., NRCS 590 standard, P-Index) have been developed in an attempt to reduce NPS pollution but these practices are often variable in their effectiveness (Puckett, 1995). This is, to some extent, because their effectiveness is based on estimates made by models that do not consider the spatial variability of agricultural landscapes or the temporal dynamics of nutrient and pollutant transport processes (Dahlke et al., 2012; Easton et al., 2008). New tools need to be able to capture spatiotemporal variability of hydrological and biogeochemical processes in order to assist watershed managers, producers, and landowners in planning agricultural management practices to reduce NPS pollution.

Surface runoff is a critical pathway of NPS pollutant transport to streams, and often it is small and variable sub-field-level areas of land that are the primary source of surface runoff and water quality degradation (Walter and Walter, 1999). These so called variable source areas (VSAs), as defined by Hewlett and Hibbert (1967), often occur in areas of watersheds that have a shallow top soil layer with high-infiltration rates overlaying a dense subsoil layer which restricts percolation out of the vadose zone (Dunne and Leopold, 1978; Easton et al., 2008; Walter and Walter, 1999). When these features are located in convergent areas of the landscape (e.g., large upslope contributing areas) the soil must be able to conduct large volumes of water through the profile rapidly, or else it saturates and becomes a runoff source area. These factors result in some areas of the landscape having low transient soil water storage capacity and are thus easily saturated during precipitation events. The location, size, and duration of saturation of these VSAs depend on variable factors including soil depth and conductivity, landscape position, and antecedent soil moisture (Needelman et al., 2004). Consequently, VSAs are difficult to model using traditional watershed models (e.g., SWAT, GWLF, HSPF), making the prioritization of 
landscape management practices challenging (Brooks et al., 2015; Dahlke et al., 2012; Dunne and Leopold, 1978; Marjerison et al., 2011; Sommerlot et al., 2013).

Walter et al. (2000) introduced the concept of hydrologically sensitive areas (HSAs) to refer to parts of the landscape where VSAs form and a pollutant source exists (e.g., manure, fertilizer). Knowledge of when and where these HSAs form could be used to prioritize landscape management strategies. For example, a nutrient management plan, often written to direct manure spreading on a seasonal basis, may suggest an operations schedule that does not take into account the location of HSAs within the target fields. Information about where these HSAs exist could be used to modify the nutrient management plan and avoid pollution causing activities during sensitive times or in sensitive areas (Hanrahan et al., 2004; Smith et al., 2007; Vadas et al., 2011).

A major challenge in modeling VSAs is their temporal variability; VSAs can evolve over a single precipitation event, as well as shift due to seasonal fluctuations in precipitation and evapotranspiration. Attempts to model this phenomenon include the Soil and Water Assessment Tool-VSA adaption (SWAT-VSA), a modification of the popular SWAT model that uses topographically derived parameters designed to better quantify the distribution of surface runoff and soil moisture from VSAs (Collick et al., 2014; Easton et al., 2008, 2011, 2010; White et al., 2011; Woodbury et al., 2014). SWAT-VSA was developed to account for runoff processes in humid, well-vegetated regions, especially those with permeable topsoil underlain by a shallow restrictive layer, by considering the influence of landscape position and antecedent soil moisture storage capacity. For instance, many soils in the Mid-Atlantic region have a substantially higher infiltration rate than the total precipitation depth of all but the most intense, convective type storms, thus runoff is generated from areas of the landscape that saturate and can no longer store 
more moisture (Easton et al., 2008). As a result the way that many traditional curve number (CN) based models, which explicitly assume an infiltration excess (or Hortonian - Horton, 1933) response to rainfall, fails to capture observed hydrologic responses (Beven, 2001). SWAT-VSA has been shown to provide more accurate predictions of soil moisture and runoff generation than the standard SWAT model in watersheds with similar physical characteristics and climate to the study area (Easton et al., 2008; Pradhanang et al., 2013; Woodbury et al., 2014).

In order to use SWAT-VSA in forecast capacity it needs to be coupled with some type of short-term weather model. Short and medium range (1-16 day) weather forecasts assimilate remote and ground observations into an atmospheric model analysis time step to initialize physically based solutions of future surface weather conditions (GFS, 2015; NCEP, 2003). These predictions of future surface weather conditions can then be used to force the SWAT-VSA model to provide forecasts of hydrological processes. The National Centers for Environmental Prediction's (NCEP) Global Forecast System-Model Output Statistic-GFS-MOS (GFS, 2015; NCEP, 2003) formerly known as the Medium Range Forecast model (MRF), initially developed by Sela $(1982,1979)$, provides forecasted surface predictions out 16 days for every location on the planet, four times a day, every single day of the year. This reliability and global coverage makes it an ideal candidate for using as the basis of management planning tool requiring reliable data sources. The GFS-MOS is also complemented by the Climate Forecast System Reanalysis (CFSR; Saha et al., 2010) that provides long histories with similar physical constructs which mitigates potential solution based biases that exist between forecasting systems (Hamill et al., 2008). These datasets, when coupled, provide contiguous estimates of weather variables, including precipitation and temperature, for any terrestrial location worldwide from 1979 to 16 days into the future. 
With the availability of high-resolution weather forecasts, great strides have been made in short-term decision support tools in agriculture and elsewhere. For instance, the Wheat Fusarium Head Blight Risk Assessment Tool uses climate modeling to predict conditions favorable to wheat blight for a 1-3 day period (http://www.wheatscab.psu.edu/riskTool_2010.html) and is credited with major reductions in fungicide use in wheat production corresponding to millions of dollars in savings. Shaman et al. (2006) developed a tool incorporating hourly and daily weather forecasts to identify sites with surface moisture that could support mosquitoes breeding. Coupling real time weather forecasts with operational hydrological modeling has also been described in recent studies using rainfall-runoff and time-series models to predict hydrologic processes at watershed scales such as streamflow or reservoir status (Abaza et al., 2014; Dutta et al., 2012; Tsai et al., 2014), however, these tools do not specifically provide predictions intended to inform field level decision making.

This study demonstrates coupling SWAT-VSA with global weather forecast (GFS-MOS) products to provide short-term hydrologic forecasts capable of guiding landscape management in real-time. The model provides two primary forecasts: hydrologic in the form of daily volumetric stream flow estimates and distributed surface hydrology in the form of sub-field level predictions of surface runoff risk probability and soil moisture.

\section{Materials and Methods}

2.1 Overview: Model development followed a four-step process. First, the base SWAT-VSA model was developed for the South Fork of the Shenandoah river watershed (Fig. 1) using historic meteorological data. Second, the model was calibrated and corroborated against United States Geologic Survey (USGS) streamflow gage data using the base model output forced by the historic meteorological data available from station records included in the quality-controlled 
119 Global Historical Climatology Network (Menne et al., 2012). Third, the corroborated model was

120 coupled with the GFS-MOS data by collecting historical, archived GFS-MOS forecasts and 121 applying these as weather forcings to the SWAT-VSA model in a hindcast procedure recreating 122 past outputs of model coupling. Finally, the GFS-MOS forced model outputs were used to 123 predict watershed level discharge and distributed hydrologic response in the watershed (note that 124 the model was not re-calibrated using the GFS-MOS data). The relationship between the base 125 input data and the resulting derived data set are shown in Fig. 2. Scripts and functions used to 126 develop the model and the various couplings can be in the github repository: 127 https://github.com/andrewsommerlot/vsa-gfs-forecast.

128 2.2 Study Area: The SWAT-VSA model was developed and tested in the South Fork of the 129 Shenandoah river watershed (HUC 02070005), with the outlet located at the USGS gaging 130 station 01628500 . The watershed has an area of $2600 \mathrm{~km}^{2}$ located in the Shenandoah Valley in 131 North-Central Virginia (Fig. 1). Land cover in the Shenandoah watershed is $50 \%$ forest, and 132 almost entirely located in the steep mountain headwaters. Agricultural lands occupy $38 \%$ of the 133 watershed and are located in the valley, urban areas occupy $11 \%$, and the remaining $1 \%$ of the 134 basin is covered by water (Homer et al., 2015). Soils are silt loams and silty clay loams, with 135 slopes up to $60 \%$, elevations of 310 to $1336 \mathrm{~m}$ and the watershed is located in the humid 136 continental climate with a yearly average rainfall of $1057 \mathrm{~mm}$ (Mohamoud, 2004).

137 2.3 SWAT Model Description: The SWAT model, developed by USDA-ARS, is a process based, 138 semi-distributed watershed model meant to provide predictions of the impact of agricultural 139 landuse on water quantity and quality (Arnold et al., 1998, 2012; Gassman et al., 2007). SWAT 140 uses weather, elevation, soil, land cover, and land management data to simulate surface and 141 subsurface hydrology and various chemical and sediment fluxes. Required spatial data include 
143 tables that contain model required parameters. Simulations require meteorological input data

144 including precipitation, temperature, relative humidity, wind speed, and solar radiation.

145

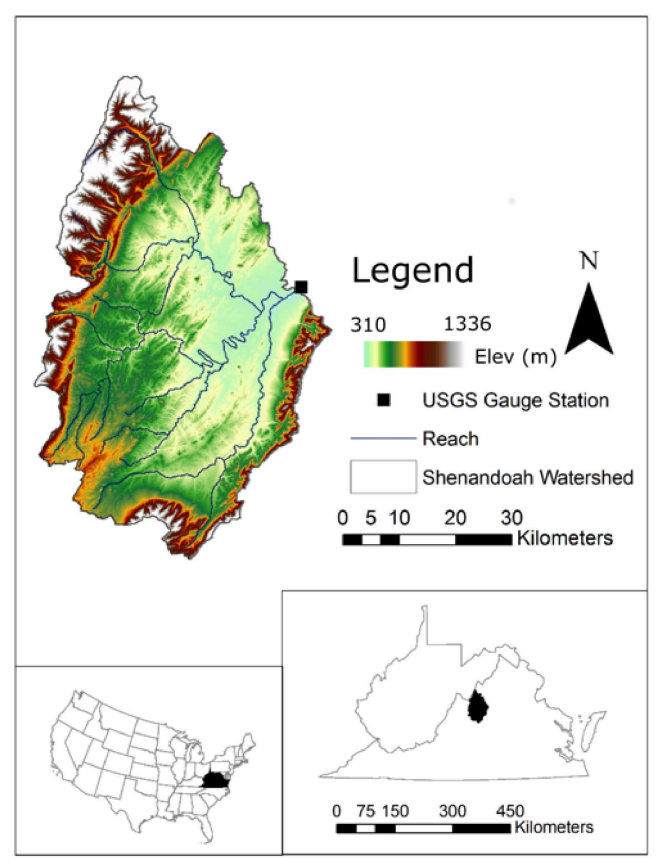

147 Figure 1. Study Area: South Fork (SF) of the Shenandoah river watershed in north central VA, shown with elevation features and general location with respect to adjacent states and the U.S.

SWAT lumps unique combinations of soil type and landuse (and slope if desired) into hydrologic response units (HRUs) during the initialization process. While this process reduces computational complexity, it effectively ignores the underlying spatial distribution of the input data. Thus, all HRUs containing the same soil type, land use (and slope class) have identical properties irrespective of where they are located. In VSA watersheds, runoff generating areas are a controlled by their location within a subbasin: VSAs are likely to occur in portions of the

156 landscape with shallow soils underlain by some sort of restrictive layer, large upslope contributing areas, flattening slopes, or any combination of the three. To account the formation 
and contribution of VSAs, SWAT-VSA incorporates a hybrid topographic wetness index-soil layer, which is then used in place of the standard soil layer in HRU generation (Easton et al., 2008). The topographic wetness index (TI) is a unitless metric categorizing the saturation potential of areas in a watershed and ranges from 1 , the least likely to saturate, to $n$, the most prone to saturation (Easton et al., 2008). Runoff and soil moisture distributions are then explicitly linked to the topographic wetness index. While the wetness classes can be used in HRU delineation instead of a soil map, SWAT still requires specific soil properties associated with the soils map (e.g., SSURGO). Thus, in SWAT-VSA soil properties are areally weighted and averaged for each TI class. This practice does not drastically affect model results because soil genesis is, at least partially, driven by topography (Easton et al., 2008; Page et al., 2005; Sharma et al., 2006; Thompson et al., 2006). with a saturation-excess modified $\mathrm{CN}$ resulting in an approximation of the runoff equation described by (Schneiderman et al., 2007):

$172 \quad q_{i}=\frac{P_{e}^{2}}{P_{e}-\sigma_{e}}$

173 where $q_{i}$ is the surface runoff for any given $\mathrm{HRU}, P_{e}$ is the amount of rainfall after runoff begins $174(\mathrm{~mm})$, and $\sigma_{e}(\mathrm{~mm})$ is the maximum effective soil moisture storage defined uniquely for each TI 175 class (Easton et al., 2008).

176 2.4 Model Initialization: The SWAT-VSA model was initialized for the South Fork of the 177 Shenandoah River watershed (Fig. 1) using ArcSWAT2012 and an ArcSWAT plugin, 178 TopoSWAT (available from http://ww2.bse.vt.edu/eastonlab/), developed to automatically 179 generate the TI-Soil hybrid layer used for SWAT-VSA initialization (Fuka et al., 2016). 180 TopoSWAT provides the necessary soil data to calculate TI via linkage to the United Nations 
Food and Agriculture Organization (FAO) soils database (IUSS, 2007). Other spatial inputs

182 include landuse from the National Land Cover database (Homer et al., 2015), and a combination 183 of $3 \mathrm{~m}$ and $10 \mathrm{~m}$ resolution DEMs from the United States Geologic Survey (GHCN) National 184 Elevation Dataset (NED) resampled to $3 \mathrm{~m}$ covering the study area. No thresholds were applied 185 during HRU definition in order to generate a full-HRU distribution. The final initialization resulted in five subbasins and 859 HRUs over the study domain. data used for model calibration and corroboration. The second, referred to as archived forecasts, was used to validate the framework's capability to forecast without waiting months to collect

190 future GFS-MOS forecast data. The meteorological data set used in calibration and corroboration 191 of the base model consisted of redimensioned CFSR data bias corrected with data from GHCN stations. The CFSR data set provides the required meteorological parameters to force the base model: precipitation $(\mathrm{mm})$, minimum and maximum temperature $(\operatorname{deg} \mathrm{C})$, percent relative humidity, wind speed $(\mathrm{m} / \mathrm{s})$, and solar radiation $\left(\mathrm{MJ} / \mathrm{m}^{\wedge} 2\right)$ at a daily time step (Fuka et al., 2013). CFSR was chosen as the base data set to make this method as widely applicable as possible, as it provides all necessary parameters on a global grid and contains no missing data. Precipitation data from five GHCN rain gauges located within the study area were used to bias correct the

198 CFSR data as the initial analysis revealed a bias in the CFSR data. Gauge stations used were 199 UCS00448941, USC00442208, USC00448062, USC0044322 and USC00445096, accessed 200 through the National Centers for Environmental Information Climate Data Online search tool.

201 Meteorological data from both the CFSR and GHCN rain gauge data sets were 202 interpolated to the SWAT-VSA model subbasin centroids using inverse distance weighting 203 (IDW) squared. Bias correction of CFSR precipitation was performed by modifying functions 
205 Gudmundsson et al. (2012). The bias correction was applied by separating each precipitation 206 data set into unique months, and creating a Cumulative Distribution Function (CDF) for each month. This method is modified from a similar process of CDF mapping described in Girvetz et al. (2013), following their suggestion to produce monthly CDF functions for daily weather data.

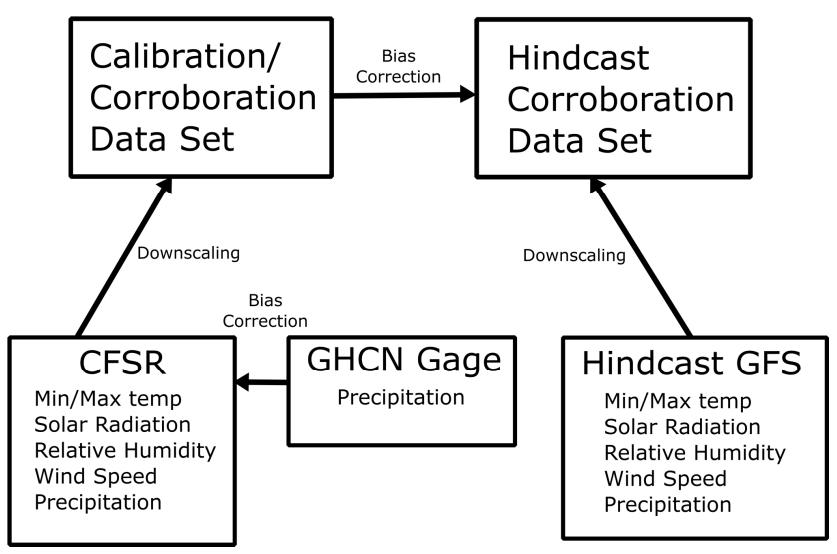

Figure 2: The relationship between the collected meteorological data and the resulting data sets used for the SWAT-VSA linkage calibration, corroboration, and hindcast.

2.5 Archived GFS-MOS Forecasts: The streamflow forecast corroboration was performed by

214 collecting archived GFS-MOS forecasts through a hindcast procedure. Uncorrected "raw" GFS-

215 MOS forecasts up to eight days in advance were available in GRIB2 format through the NOAA NOMADS service (Rutledge et al., 2006). Each file in the data set contained forecast data at a 0.5 degree resolution. (GFS, 2015). An R script was written to catalog and organize the location of each GRIB2 file in the available data set. The result was a catalog of over 23,000 remote file locations of data storing world-wide uncorrected GFS-MOS forecasts for 1 through 8 days in the future from the GFS-MOS model run. Dates ranged from May 2013 through March 2015 at the time the catalog script was run and included forecasts updates at 6-hour intervals. A second $\mathrm{R}$ script optimized for parallel implementation on NCARs Yellowstone Geyser super computer 223 cluster was used to download, convert, and summarize the uncorrected GFS-MOS data set into a 
daily time series of weather data required for SWAT-VSA model inputs. This script applied a bounding box around Virginia and parts of West Virginia to reduce the computational time necessary to produce the daily time series. Parallelization of this portion of the data collection and formatting reduced computational time from over 40 days to about 6 hours. Table 1 below summarizes the methods used to distill the full six terabyte archived GFS-MOS forecasts into daily time series files with all necessary SWAT weather input variables. In total, eight daily time series files were created from May 2013 through March 2015, one for each forecast day.

Table 1. Global Forecast System (GFS-MOS) model parameters used in the SWAT-VSA model.

\begin{tabular}{|l|l|l|l|l|l|}
\hline $\begin{array}{l}\text { Weather } \\
\text { Parameter }\end{array}$ & \multicolumn{2}{l}{$\begin{array}{l}\text { Provided Time } \\
\text { Step }\end{array}$} & $\begin{array}{l}\text { Required } \\
\text { Time } \\
\text { Step }\end{array}$ & \multicolumn{1}{l|}{$\begin{array}{l}\text { Aggregation } \\
\text { Method }\end{array}$} & \multicolumn{2}{l|}{$\begin{array}{l}\text { Provided } \\
\text { Units }\end{array}$} & \multicolumn{1}{l|}{ Required Units } \\
\hline Precipitation & 4 hour & Daily & Summation & mm & mm \\
\hline $\begin{array}{l}\text { Minimum } \\
\text { Temperature }\end{array}$ & 4 hour & Daily & Minimum & Kelvin & Degrees Celsius \\
\hline $\begin{array}{l}\text { Maximum } \\
\text { Temperature }\end{array}$ & 4 hour & Daily & Maximum & Kelvin & Degrees Celsius \\
\hline $\begin{array}{l}\text { Relative } \\
\text { Humidity }\end{array}$ & 4 hour & Daily & Average & Percentage & Percentage \\
\hline $\begin{array}{l}\text { Wind Speed } \\
\text { Solar }\end{array}$ & 4 hour & Daily & $\begin{array}{l}\text { Vector } \\
\text { Addition }\end{array}$ & $\begin{array}{l}\text { u and v } \\
\text { direction } \mathrm{m} / \mathrm{s}\end{array}$ & Directionless m/s \\
\hline
\end{tabular}

The resulting daily time-series of weather data were not contiguous due to missing files

234 in the GFS-MOS data set and server errors during download; 41 time steps of data were missing in the forecast data set. An imputation process was performed on the data employing time series methods and the fGarch R package (Hyndman and Khandakar, 2008; Wuertz et al., 2009).

237 Missing data from the original set were replaced with residual-corrected corresponding values 238 from Autoregressive Integrated Moving Average time series models. In order to use the weather 239 data directly in the SWAT model, the data were interpolated to SWAT-VSA model subbasin 
centroids using the same IDW squared procedure employed for CFSR in order to keep 241 consistency with the calibration and corroboration data sets. These methods were repeated for each of the eight weather forecast data sets.

The full forecast data sets were further preprocessed using a dynamic downscaling 244 procedure including IDW squared and bias correction. All parameters of the archived forecast data were bias corrected using the same procedure as described for the CFSR precipitation data used for calibration. The redimensioned CFSR data set was available through August 2014, 247 limiting the final GFS-MOS archived forecasts to the same end date for the bias correction 248 procedure. The GFS-MOS forecasts were bias corrected using the interpolated rain gauge data 249 for precipitation and CFSR data for the remaining parameters. Once gauge and CFSR data are 250 collected and interpolated, the bias correction of GFS-MOS data is repeatable for actual forecasts 251 in real-time following this method. The GFS-MOS archived forecasts were split into two equal 252 parts, the first representing past values and the second representing future values. The separation allowed the GFS-MOS data to be bias corrected as if the portion representing future values was actually composed of future forecasted values, while measured flow data were available. The relationship between this data set, the calibration/corroboration data set, and the input meteorological data is illustrated in Fig. 2.

2.6 Sensitivity Analysis: Prior to SWAT-VSA model calibration, a sensitivity analysis was performed using the SWATmodel (Fuka et al., 2014) and hydroPSO (Zambrano-Bigiarini and Rojas, 2013) packages in R. SWATmodel provides optimized read/write access to model files 260 while using the lhoat() sensitivity analysis function from hydroPSO. The sensitivity analysis was 261 applied on model runs from January 12004 through December 31 2014. hydroPSO runs a Latin262 Hypercube one-at-a-time process on the selected parameters and outputs parameter sensitivity 
rankings (Zambrano-Bigiarini and Rojas, 2013). Flow parameters were selected based on analysis of preliminary runs of the initialized model. In addition, the preliminary analysis suggested some classically sensitive parameters be applied independently in each subbasin. The $\mathrm{CN}$, channel hydraulic conductivity, and Manning's n values were separated to allow unique values at the subbasin scale. Base flow and soil parameters were the most sensitive parameters (Table 2). Snow melt/accumulation parameters were also sensitive, including snow pack lag factor, snowmelt temperature, and snowfall temperature. Surface runoff lag coefficient and ground water delay factors also ranked in the top half of the parameter list (Table 2). The CN, 271 channel conductivity, and Manning's N did not all rank as high as expected since each of these 272 parameters are unique to a subbaisn, their sensitivity was lower than if applied to the entire 273 basin; however the increase in spatial resolution of these parameters was considered critical to 274 adequate model predictions at the field scale. Thus, all parameters applied at the subbasin scale were included in the calibration. Twenty-five parameters were selected from the sensitivity analysis for model calibration (Table 2). The $\mathrm{CN}$, channel conductivity, and Manning's $\mathrm{N}$ values

277 for all five subbasins and the remaining 10 highest ranking parameters were selected.

Table 2. Model parameters selected for sensitivity analysis: ranking, method of calibration 279 adjustment, range, ranking, and final calibrated values.

\begin{tabular}{|c|c|c|c|c|c|c|c|}
\hline 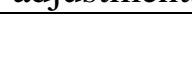 & 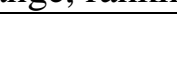 & & & Rang & & & Calibrated \\
\hline Parameter & Subbasin & File & Method & Min & Max & Ranking & Value \\
\hline Alpha_BF & all & $* . g w$ & replace original with & 0.5 & 1.5 & 1 & 0.59 \\
\hline Sol_AWC & all & *.sol & multiply original by & 0.5 & 1.5 & 2 & 0.89 \\
\hline ESCO & all & $*$.hru & replace original with & 0.1 & 1 & 3 & 0.91 \\
\hline Sol Depth & all & $*^{*}$.sol & multiply original by & 0.5 & 1.5 & 4 & 0.46 \\
\hline SFTMP & all & basin & replace original with & -5 & 5 & 5 & -1.62 \\
\hline $\mathrm{CN} 2$ & 4 & *.mgt & multiply original by & 0.7 & 1.3 & 6 & 0.63 \\
\hline SMTMP & all & basin & replace original with & -5 & 5 & 7 & -1.51 \\
\hline TIMP & all & .basin & replace original with & 0 & 4 & 8 & 0.07 \\
\hline $\mathrm{CN} 2$ & 2 & *.mgt & multiply original by & 0.7 & 1.3 & 9 & 0.63 \\
\hline $\mathrm{CN} 2$ & 5 & *.mgt & multiply original by & 0.7 & 1.3 & 10 & 0.60 \\
\hline
\end{tabular}




\begin{tabular}{|c|c|c|c|c|c|c|c|}
\hline SURLAG & all & .basin & replace original with & 0 & 15 & 11 & 142.7 \\
\hline CH_K2 & 3 & *.rte & replace original with & 0 & 200 & 12 & 0.936 \\
\hline CH_N2 & 3 & *.rte & replace original with & 0.016 & 0.15 & 13 & 0.087 \\
\hline CH_N2 & 2 & $*$.rte & replace original with & 0.016 & 0.15 & 14 & 0.090 \\
\hline SMFMN & all & .basin & replace original with & -5 & 5 & 15 & 1.09 \\
\hline CH_K2 & 5 & *.rte & replace original with & 0 & 200 & 16 & 0.051 \\
\hline CH_K2 & 2 & *.rte & replace original with & 0 & 200 & 17 & 0.082 \\
\hline GW_delay & all & $* . \mathrm{gw}$ & replace original with & 0.5 & 2000 & 18 & 1592 \\
\hline CH_K2 & 1 & *.rte & replace original with & 0 & 200 & 19 & 126.9 \\
\hline CH_N2 & 1 & *.rte & replace original with & 0.016 & 0.15 & 20 & 0.069 \\
\hline CH_K2 & 4 & *.rte & replace original with & 0 & 200 & 21 & 154.4 \\
\hline Ksat & all & $*$.sol & multiply original by & 0.5 & 1.5 & 22 & Not Calibrated \\
\hline $\mathrm{CN} 2$ & 3 & $* . \mathrm{mgt}$ & multiply original by & 0.7 & 1.3 & 23 & 0.74 \\
\hline $\mathrm{CN} 2$ & 1 & *.mgt & multiply original by & 0.7 & 1.3 & 24 & 0.61 \\
\hline GW_REVAP & all & $* . \mathrm{gw}$ & replace original with & 0 & 0.2 & 25 & Not Calibrated \\
\hline RCHRG_DP & all & *.gW & replace original with & 0 & 1 & 26 & Not Calibrated \\
\hline CH_N2 & 5 & *.rte & replace original with & 0.016 & 0.15 & 27 & 0.87 \\
\hline GWQMN & all & *.gW & replace original with & 0 & 500 & 28 & 471 \\
\hline SMFMX & all & .basin & replace original with & -5 & 5 & 29 & Not Calibrated \\
\hline CH_N2 & 4 & *.rte & replace original with & 0.016 & 0.15 & 30 & 0.090 \\
\hline REVAPMN & all & *.gw & replace original with & 0 & 500 & 31 & Not Calibrated \\
\hline ESCO & all & .basin & replace original with & 0.1 & 1 & 32 & Not Calibrated \\
\hline EPCO & all & .basin & replace original with & 0.1 & 1 & 33 & Not Calibrated \\
\hline
\end{tabular}

$281 \quad 2.7$ Model Calibration: The initialized model was calibrated to USGS gage flow data on a daily

282 time step from January 12004 through December 31 2012, on the Yellowstone Geyser super

283 computer cluster, a 16 node, 16,000 GB ram platform located at the National Center for

284 Atmospheric Research Wyoming Supercomputing Center. A similar combination of the

285 SWATmodel (Fuka et al., 2014) and hydroPSO (Zambrano-Bigiarini and Rojas, 2013) R

286 packages as described in the sensitivity analysis was used to run the model and perform

287 necessary statistical analysis on model results. Model calibration was run on one node of Geyser,

288 using 40 cores and 1000 GB of memory in parallel. The SWATmodel package was used to run

289 SWAT2012 on a Linux operating system and to provide read/write functionalities for SWAT

290 input and output files. The read and write functions were included in an input/output wrapper 
that allowed the framework to utilize the output parameters of the calibration and sensitivity analysis procedures. The hydroPSO package was used as the calibration engine to maximize the fitness of the model and to apply parallel computing techniques to reduce the computation time. All $\mathrm{R}$ functionalities were written into a script portable to the parallel Geyser platform. The resulting parameter values following the calibration are shown in the Table 2 .

2.8 SWAT-VSA Hindcast: A hydrologic hindcast was performed to evaluate the model performance in predicting daily watershed discharge an, more critical for management applications, the sub field scale spatial soil moisture predictions. The meteorological data sets prepared for hindcast validation and calibration/corroboration were used to initialize unique SWAT-VSA model runs for each day in the hindcast period, recreating the live forecast procedure the model is intended to perform. Each unique model run was forced with 12 years of meteorological data, the last eight days of the run defined by the corresponding day and forecast level (i.e., $24 \mathrm{~h}, 48 \mathrm{~h}, 72 \mathrm{~h}$, etc.) from the meteorological data prepared for hindcasting. The remaining input was defined by the meteorological data prepared for calibration/corroboration, just as it would be in a live forecast. The last eight days of each SWAT-VSA daily watershed discharge time series output, representing the hydrologic forecasts, was saved and separated to eight unique time series by forecast level. Thus, time series for all eight hindcast days could be directly compared to measured volumetric flow at the watershed outlet. In total, 462 consecutive days of hindcast runs were performed for each forecast level, from May 27, 2013, to August 31, 3102014.

311 2.9 Distributed Forecast Output: The spatially distributed forecast was a binary classification 312 procedure defining areas as saturated or unsaturated. During model initialization a raster 313 containing spatial references to each TI class in the SWAT-VSA model was created. The raster 
was then populated with binary hindcast model outputs from a single day in the spatial hindcast corroboration. To calculate the binary hindcast the HRU soil moisture level predicted by the model (in mm over the entire soil profile) was divided by the soil depth of the HRU to return the percent saturation metric. A threshold of $80 \%$ of the soil profile as saturated was used to define each HRU output as saturated (greater than or equal to $80 \%$ ) or not saturated (less than $80 \%$ ) (Lyon et al., 2006). Final classifications mapped to TI class distribution were calculated through a majority-vote aggregation procedure, an ensemble of the spatial output of SWAT-VSA aggregated to the TI class distribution. Multiple HRUs correspond to each TI class in the output raster, thus to calculate the final saturation classification all HRUs corresponding to a unique TI classes were polled and the majority vote (either saturated or not saturated) was adopted as the final label for that TI class. The resulting output was a $3 \mathrm{~m}$ resolution raster displaying a binary saturation classification for a single day forecast. This process was repeated for two unique days, December 19 2015, and December 26 2015. Data defining saturated and unsaturated areas were collected on both of these days in various locations throughout the SF of the Shenandoah watershed for corroboration. Corresponding spatial model outputs were defined by calculating the ratio of raster cells labeled as saturated to total number of cells within each of these areas.

330 This ratio was considered the predicted probability of the entire area to be saturated. Spatial data 331 for a total of 49 sub field areas were collected over the two days, 24 for December 19, and 25 for 332 December 26, with 37 total saturated areas and 12 total unsaturated areas. A simplified flow of 333 inputs and outputs in the SWAT-VSA framework is shown in Fig. 3. 


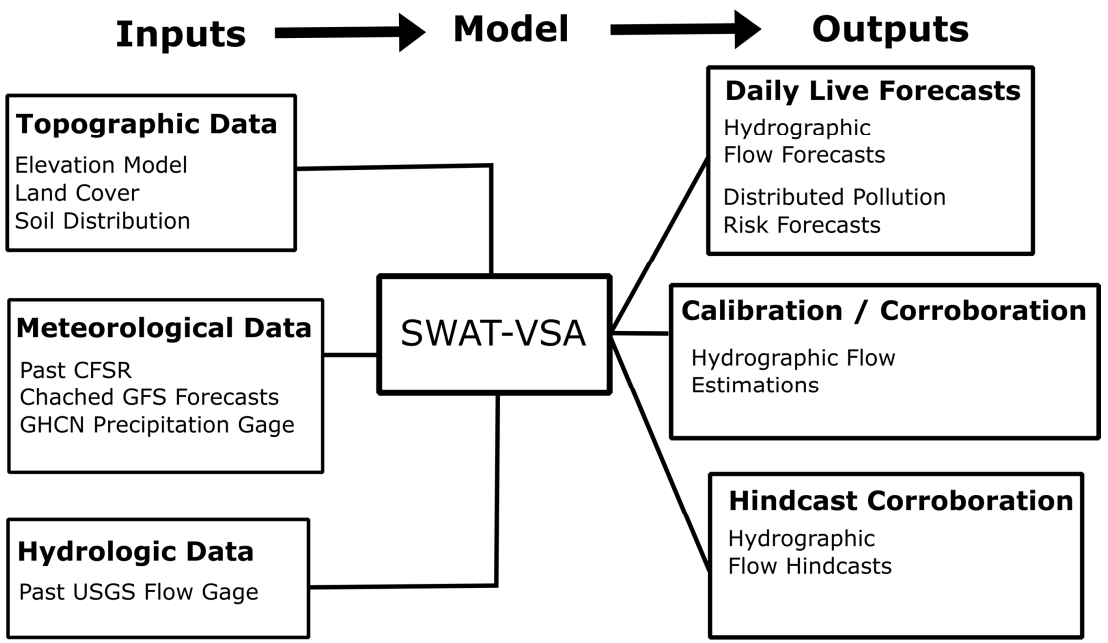

335 Figure 3: Simplified SWAT-VSA framework showing relationship and information flow between inputs and outputs.

\section{Results}

339 3.1 Archived GFS-MOS Forecasts: The archived GFS-MOS forecasts were bias corrected using

340 station data in the watershed. The measured station data contained greater maximum values

341 shown by the longer tails in Fig 4. The uncorrected GFS-MOS data increases almost linearly

342 until the $0.9 \mathrm{CDF}$ probability threshold, generally over predicting precipitation and then, above

3430.9 CDF probability, under predicting precipitation (Fig. 4). The corrected GFS-MOS

344 precipitation data more closely follows the station data shape, and captures more of the larger

345 precipitation events, but fails to capture the largest events $\left(>60 \mathrm{~mm} \mathrm{~d}^{-1-}\right)$. In general, the 346 uncorrected archived GFS-MOS forecasts have a lower probability of containing a precipitation

347 value equal to or less than a single day value of $8 \mathrm{~mm}$, and a greater probability of containing a

348 value equal to or less than a single day value of $10 \mathrm{~mm}$ or more. In each forecast day, the 349 maximum values are increased by the bias correction method, which extends the cumulative 350 probability distribution curve towards the station data maximums. This suggests that the bias 351 correction method was able to improve the archived GFS-MOS forecasts in relation to the 352 measured precipitation while still preserving the structure of the GFS-MOS data. 

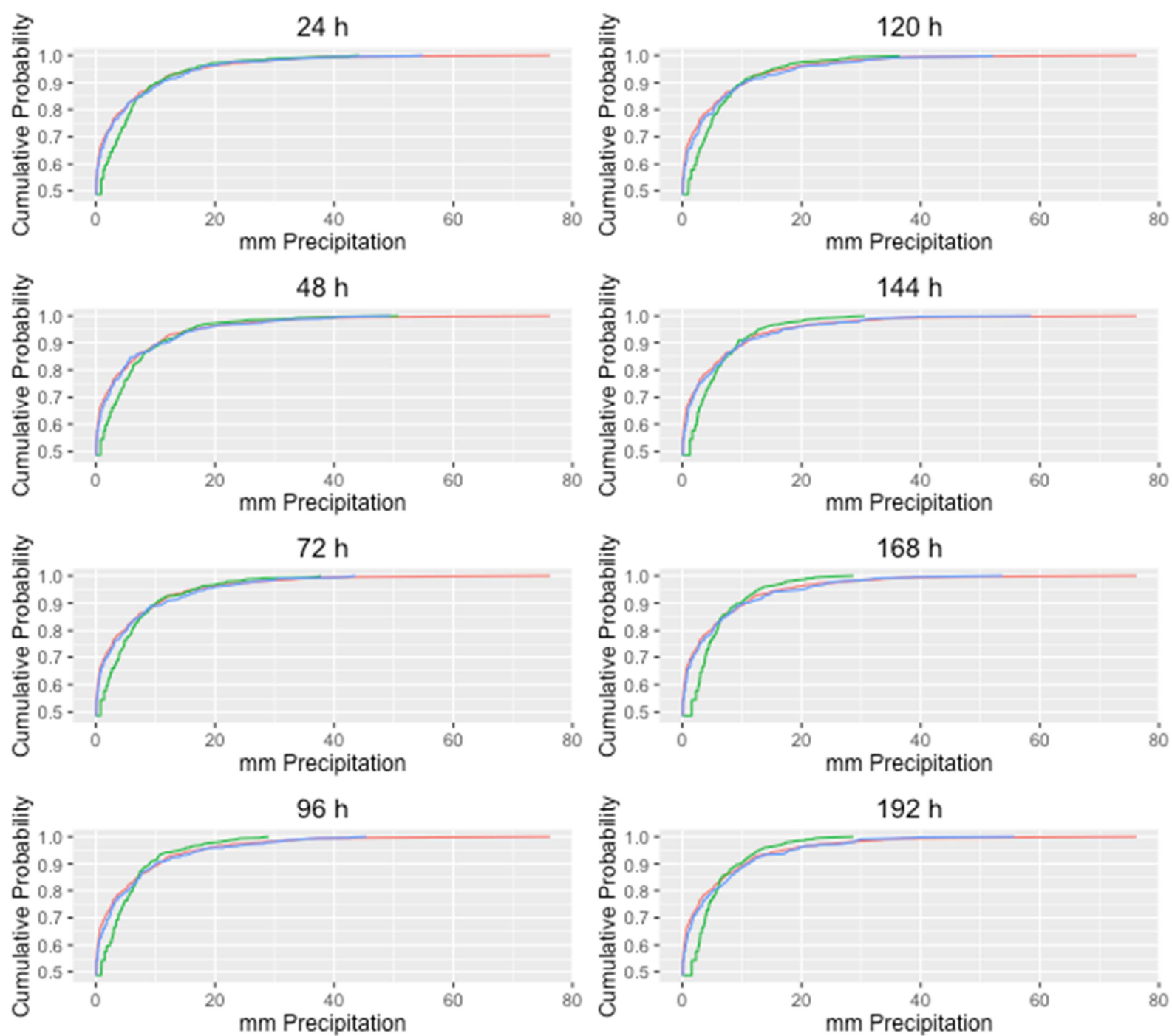
354 Figure 4: Un-bias-corrected and bias corrected precipitation data. Red lines are station data,
355 green lines are raw un-bais-corrected archived GFS-MOS forecasts, and blue lines are bias corrected archived GFS-MOS forecast.

3.2 Model Calibration and Corroboration Results: The SWAT-VSA model was able to predict the watershed level discharge relatively well on a daily basis over the calibration period January 1, 2005 through December 31, 2010 (Fig. 5), with an NSE of 0.6 in accordance with the commonly cited acceptable performance categorization of Moriasi et al. (2007). The model tended to under-predict peak flows for this period, likely due to the CFSR meteorological 363 forcings, which tend to under predict precipitation particularly from convective type storms 
364 (Fuka et al., 2013). The model was corroborated from January 12012 - August 31 2014, and 365 again showed adequate model predictive ability on a daily basis (NSE 0.5, Fig. 6). This corroboration period was chosen to include that of the GFS-MOS hindcast corroboration periods,

367 allowing for a direct comparison between standard model performance and the model 368 performance in forecast mode.

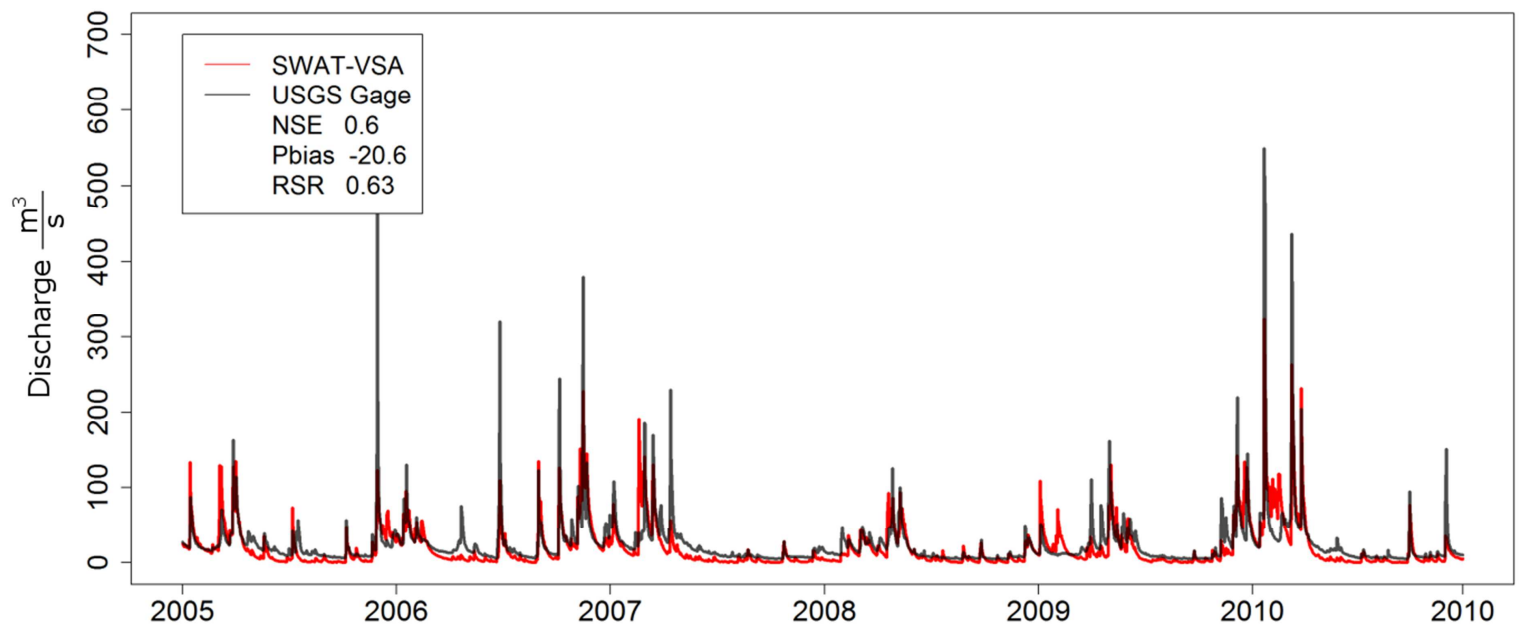

Figure 5: Observed and predicted stream flow at the watershed SF Shenandoah outlet during the calibration period.

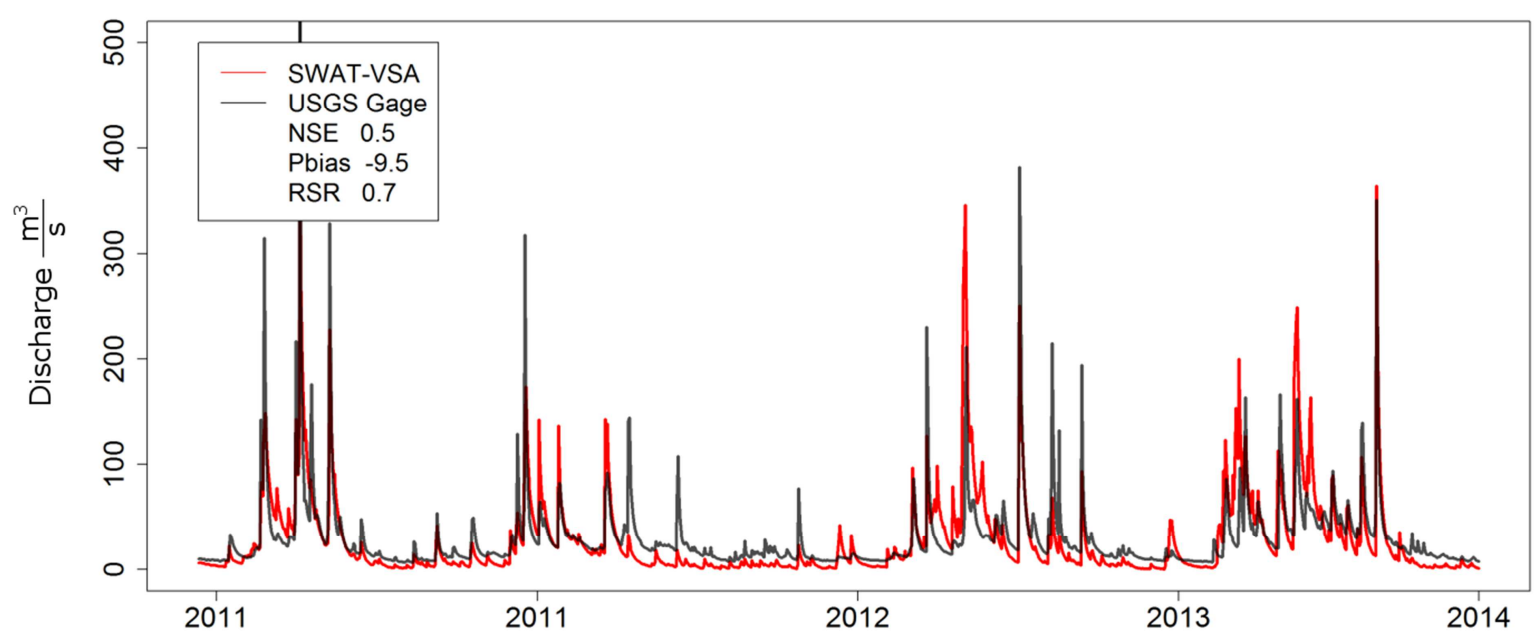

Figure 6: Observed and predicted stream flow at the SF Shenandoah watershed outlet during the corroboration period. 

comparing the daily flow predicted by the hindcast procedure to the USGS flow measurements from the gage station. The test period corresponded to the maximum amount of bias corrected archived GFS-MOS forecast data available after processing. The final corroboration range was May 192013 to August 30 2014. Results of the forecast corroboration showed acceptable flow predictions for forecast days 1-2, satisfactory for days 3-4 (Fig. 7) and unsatisfactory predictions for days 5-8 (Fig 8). The NSE metric in hindcast corroboration is not meant to reflect the usefulness of the forecast model in informing field level management, however, it does provide a method for assessing the fit of each predicted data set with respect to observed data, and is consistent with the calibration and corroboration metrics for comparative purposes. The Area Under Curve (AUC) metric described in the following sections and used to assess sub-field level predictions, is more suited to assessing the model efficacy in informing field level management. The corroboration results for all flow forecasts are summarized in the Table 3.

Table 3: Predicted flow hindcast corroboration statistics.

\begin{tabular}{|l|l|l|l|}
\hline Flow Forecast & NSE & Pbias & RSR \\
\hline 1 Day* & 0.5 & -10.2 & 0.7 \\
\hline 2 Day* & 0.5 & -6.9 & 0.7 \\
\hline 3 Day* & 0.4 & -3.0 & 0.8 \\
\hline 4 Day* & 0.4 & 0.2 & 0.8 \\
\hline 5 Day & 0.3 & 7.6 & 0.9 \\
\hline 6 Day & 0.2 & 7.6 & 0.9 \\
\hline 7 Day & 0.1 & 4.2 & 0.9 \\
\hline 8 Day & 0.1 & 6.4 & 0.9 \\
\hline
\end{tabular}

*Acceptable daily predictions, NSE ranging from 0.4 to 0.5 .

391 The hindcast was able to capture the timing of storm events for all forecast days, however, there was a tendency to under predict low flow values in days 1-3, quantified in the 

due to greater variation in weather parameters (Fig. 4).
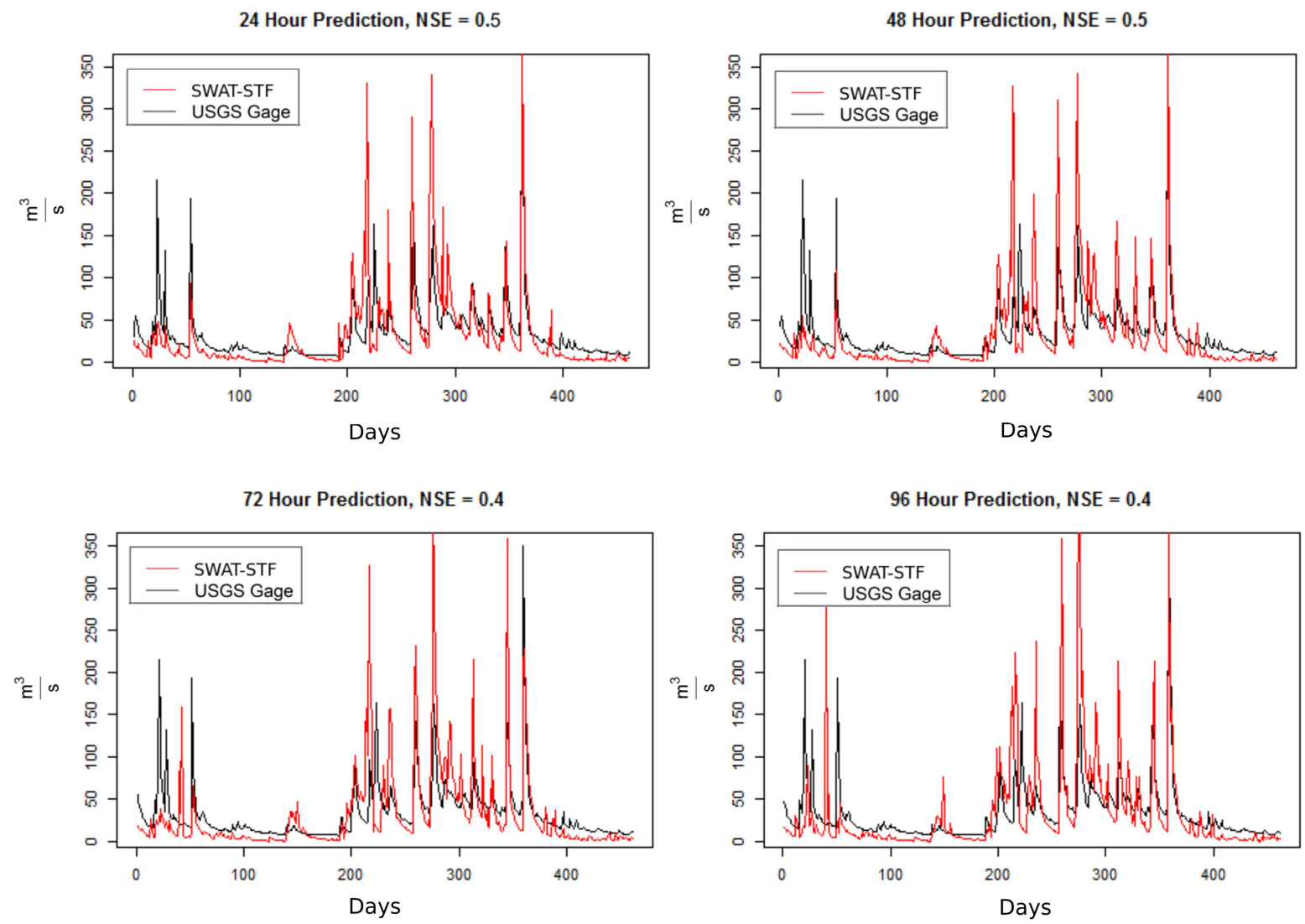

Figure 7. Volumetric flow estimates for forecast days 1 - 4 from the GFS-MOS hindcast forced model at the SF Shenandoah watershed outlet, shown with NSEs.

The unsatisfactory predictions for forecast days 5-8 were due to the precipitation hindcast data under predicting multiple rainfall events within one or two weeks of each other, especially in the late spring/early summer when convective thunder storms contribute to high runoff variability. The abrupt reduction in accuracy in the weather hindcast data shows the GFS-MOS is not able to effectively capture high precipitation variability beyond a 96-hour period. It is also 
406 worth mentioning that non 24-hour time step aggregates of the hindcast data could possibly 407 provide satisfactory flow forecasts. This drop-off in NSE after the 48-hour forecast could be 408 misleading as there are multiple sub-daily forecasts in-between the 24 and 120 hour data sets that 409 could yield satisfactory results. In addition, the NSE metric weights good predictions of extreme 410 values higher than good predictions of low values and since the hydrologic predictions beyond 41196 hours could not predict high flows very well, their accuracy was much lower as quantified by 412 the NSE metric. The hindcast overall shows an increase in extremes: many low flows are under 413 predicted, and many high flows are over predicted. This is likely due the difference in variance in 414 the archived GFS-MOS forecast and CFSR precipitation sets. GFS-MOS tends to contain a more 415 volatile prediction of precipitation, and the hydrologic model response is influenced by this 416 difference. Each hydrologic prediction is dependent on all previous forecasts from each model 417 run, i.e., each 72-hour forecast is dependent on the previous 24 -and-48-hour forecasts. In this 418 way, the hindcast procedure shows error propagation through the predictions which causes 419 increased volatility through the hydrologic hindcast sets. 

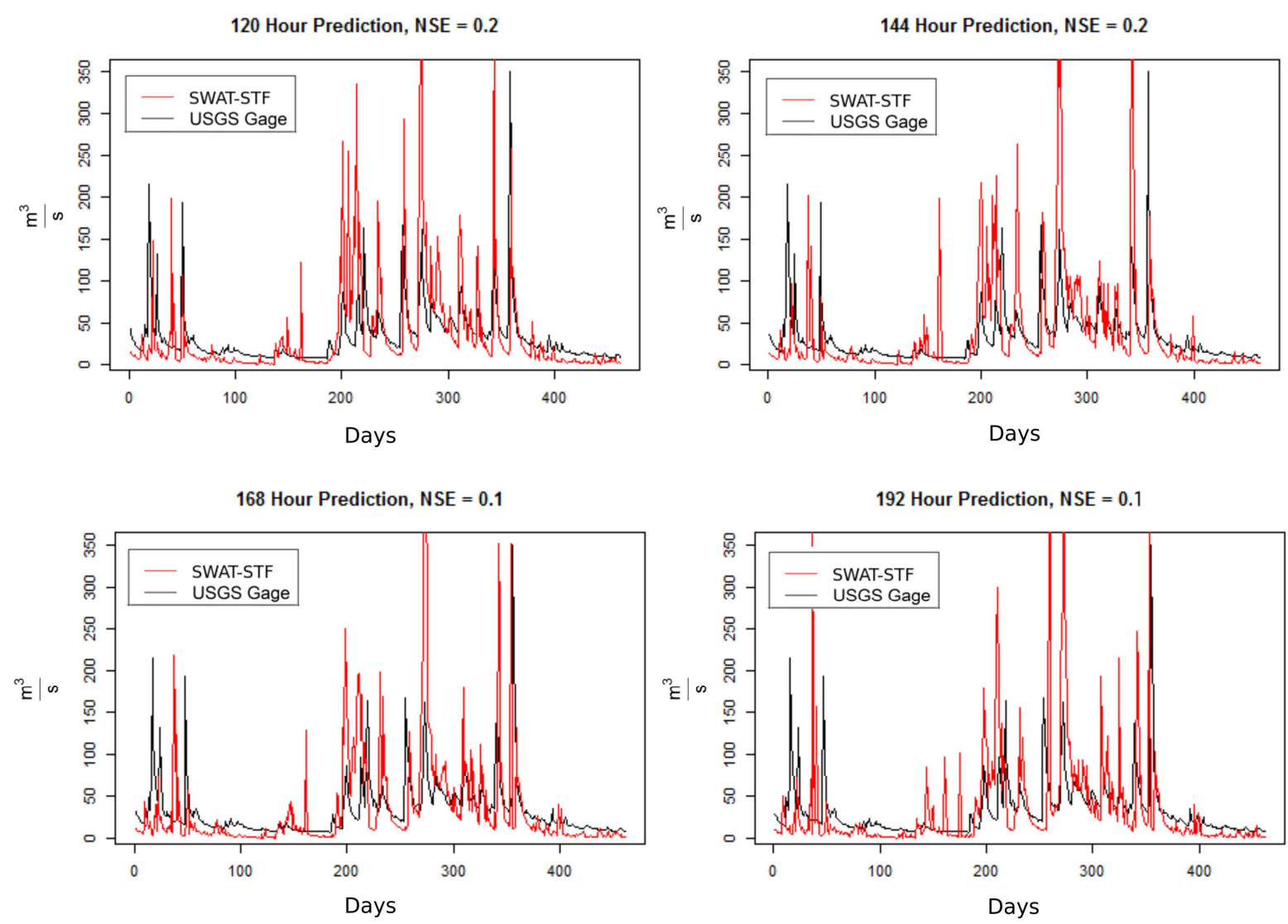

420

421

422

423

424

425

426

427

428

429

430

431

Figure 8. Volumetric flow estimates for forecast days 5-8 from the GFS-MOS hindcast forced model at the SF Shenandoah watershed outlet, shown with NSEs.

3.4 Distributed Hydrologic Predictions: A summary of the distributed model predictions of soil moisture classification is shown in Fig. 9. These predictions were selected to correspond to subfield measurements made in the watershed on December 19, and December 26 2015. The soil moisture prediction is a binary classification $3 \mathrm{~m}$ resolution raster, and the boundaries are from data collected in the field and define areas mapped as fully saturated or unsaturated. The probability that each of these areas is saturated is assumed to equal the ratio of raster cells classified by the model as saturated to total classifications contained in each measured boundary. In these example cases, all areas were predicted as saturated using a 50\% probability threshold. 


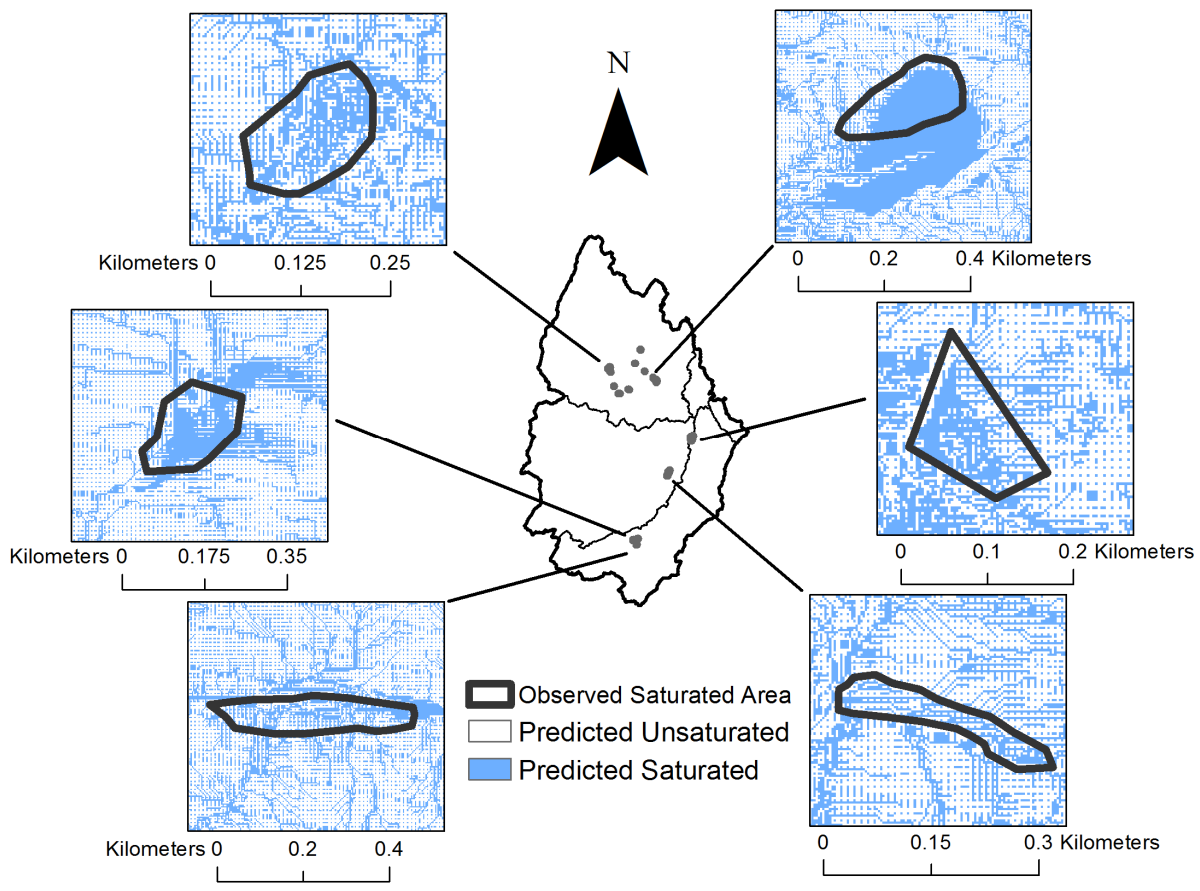

433 Figure 9. Example model output soil moisture classification forecast and observed saturated areas. Selected measured saturated areas (shown in black outline) are overlaid on top of the $3 \mathrm{~m}$ resolution spatial output of the SWAT-VSA GFS-MOS linkage. Blue indicates saturated area while white indicates unsaturated areas.

To assess the model's ability to predict distributed soil saturation, a receiver operating characteristic (ROC) curve was constructed with the predicted saturation probabilities of all areas and their measured classifications (Fig. 10). In all, 24 areas for December 19 and 25 areas for December 26 are included with 37 total saturated areas and 12 total unsaturated areas. The ROC curve shows the relationship between the true positive and false positive rate (TPR/FPR) for different classification thresholds and compares the model's ability to predict a binary 444 classification compared to random selection. The ROC curve shows a distinctive bow towards 445 the top left corner of the figure, indicating the model performs well in comparison to random 446 selection, represented by the diagonal. The classification ratio at a $50 \%$ probability with equal 447 importance given to false positives and false negatives is indicated by the dashed lines and 448 highlights a TPR/FPR ratio of $0.88 / 0.25$. The area under the ROC curve (AUC) is a common 
metric used to quantify the ROC analysis into one number. An AUC of 0.5 is interpreted as the model is equally good at predicting a binary outcome as would be a random selection, and a model with an AUC of 1 predicts all model outcomes correctly. The model's AUC from the prediction.

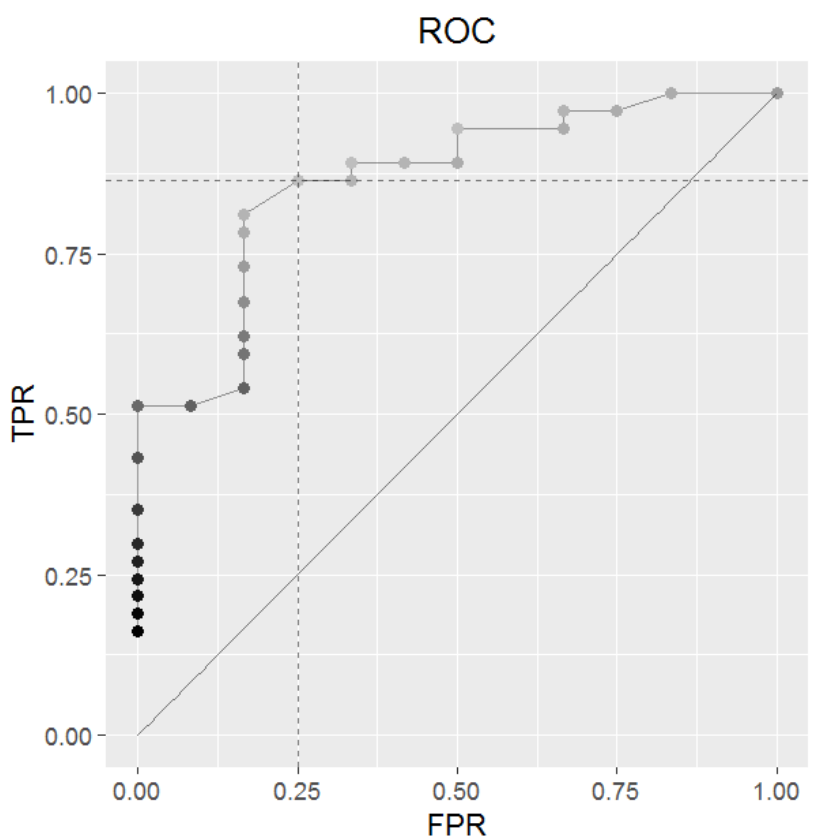

FPR

Figure 10. SWAT-VSA coupled with GFS-MOS hindcast performance as illustrated by a 456 Receiver Operating Characteristic (ROC) curve. The curve shows True Positive Rate (TPR) vs False Positive Rate (FPR) over a range of classification thresholds. Dashed lines show an optimum threshold selection along a pareto-optimal front, and the Area Under Curve (AUC) is the space between the TPR vs FPR line and the diagonal. The shading of points corresponds to increasing classification threshold from low (dark) to high (light).

Using the $50 \%$ probability threshold, all predictions for the defined areas could be compared to measured data. Figure 11 below summaries the results. Of the 49 areas measured,

464 two were incorrectly classified as saturated when they were unsaturated (false positives) and seven were incorrectly classified as unsaturated when they were saturated (false negatives). 
correctly classified as unsaturated) were predicted. In Fig. 11 the "spinning top" shape

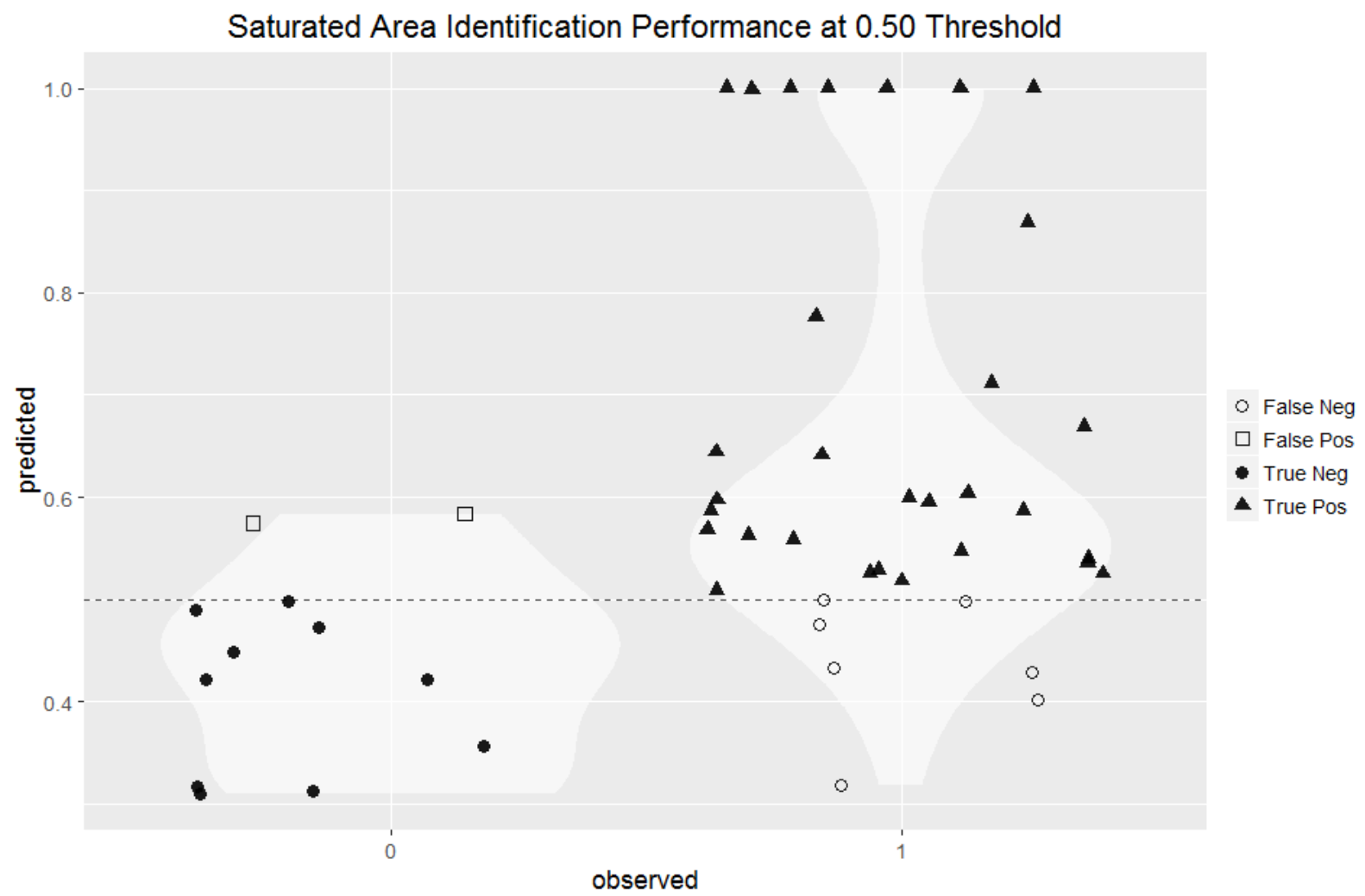

Figure 11. SWAT-VSA GFS-MOS linkage performance on saturated area spatial classification. $\mathrm{X}$-axis categories " 0 " and " 1 " indicate observed categories unsaturated and saturated, respectively. The dashed line shows 0.5 probability threshold under which all points are predicted unsaturated and above which all points are predicted saturated. Filled in points show correct classifications and hollow shapes show incorrect classifications. Distribution shapes are shaded in light gray in the background, their widths corresponding to the frequency of the probability distribution in each data set.

\section{Discussion}

The development of the SWAT-VSA GFS-MOS coupling identifies not only the locations of areas prone to soil saturation and runoff, but is also capable of predicting the probability of saturated or unsaturated areas. This information is critical to formulate landscape 
management strategies. The sub-daily updated probability maps provide scientifically grounded means for planners and producers to increase protection of areas of the landscape with high transport potential.

The model performed well spatially, providing saturated area forecasts (0.86 AUC), and was able to forecast stream flow up to 96 hours in advance with reasonable accuracy. A primary reason for lower performance on stream flow forecasts after 96 hours was a volatile GFS-MOS time series, which caused under predicted low flow events, and over predicted high flow events. The flow forecasts become increasingly unstable through the hindcast days, due to error propagation through multiple meteorological forcings, as each hydrologic hindcast greater than 24 hours depends on previous meteorological forecasts. For instance, the 8 day hydrologic hindcast includes data from eight different meteorological forecast sets run over different time periods with the same base calibration parameters. The error from these different GFS-MOS forecasts propagates through the hydrologic hindcasts, limiting the satisfactory forecast potential of the framework to 96 hours in this case. The negative Pbias from the calibration and corroboration increases, and eventually turns positive on day three of the hindcasts. It is possible that the negative Pbias of the calibration contributed to better hydrologic hindcast simulations over the first 96 hours by correcting somewhat for the inherent volatility of the the GFS-MOS

501 forecast data. This suggests more work is needed in the meteorological bias correction to account 502 for the uncertainty in the GFS-MOS forecasts. Even with this limitation, the SWAT-VSA GFS503 MOS coupling satisfactorily predicted the classification of saturated areas in over 40 field 504 locations compared to observed data. Agricultural field management operations could benefit from the framework described 506 here to identify HSAs, especially for operations such as manure spreading in fields where VSAs 
are common and manure cannot be stored for more than a few days. The saturation classification raster overlaid on aerial or satellite imagery could assist in identifying HSAs several days in advance. A producer could then plan to avoid areas in the field where a high future probability of saturation is predicted, or elect to move the operations to other fields where probabilities are lower. This could inform agricultural practices in a way that more simplified watershed models that rely on seasonal or annual estimates fall short. A web-based forecast framework that displays the relevant forecast model outputs could provide the necessary information to drive

514 field level management. The weather forecast data processing described here can be applied to real-time forecasts, allowing distributed hydrologic outputs to be used in accessible forecasts designed as decision making tools for land managers and watershed stakeholders where hydrology and NPS pathways are characterized by variable precipitation intensity, high annual rainfall, varying topography, and shallow soils. The framework could be applied to many other areas of the humid, temperate US, and indeed other regions globally, [the Nile Basin for instance, Wagena et al. (2016)] where topography and soil characteristics govern the formation of runoff source areas. In areas with deep topsoil with no restrictive layer, low conductivity soils and/or relatively flat topography, such as the Great Plains or Southeast U.S., the framework described here may be less applicable, however the GFS-MOS-watershed model coupling could be easily adapted to work with more region specific models, such as the standard SWAT model.

\section{Conclusions}

Distributed hydrologic models like SWAT-VSA can be used to provide real time and 528 short term hydrologic forecasts. In this study, a framework consisting of the SWAT-VSA model 529 and the CFSR and GFS-MOS gridded weather models was developed to provide daily 
volumetric flow forecasts and distributed saturation probability predictions for the South Fork of

531 the Shenandoah watershed in north-central Virginia. A unique data set of archived GFS-MOS

532 weather forecasts was used to perform a hindcast corroboration of the model predictions. The

533 archived GFS-MOS forecast data set was preprocessed in a manner repeatable with real-time

534 weather forecasts from the GFS-MOS model. The hindcast procedure provided satisfactory

535 volumetric flow forecasts at the watershed outlet up to 96 hrs into the future, with NSEs $0.4-0.5$

536 for daily model runs over a fifteen-month period. The ability of the SWAT-VSA model to

537 provide distributed hydrologic outputs based on TI/landuse defined HRUs allows the forecast

538 system to make distributed hydrology forecasts in addition to hydrologic flow predictions.

539 Distributed forecasts could be used to inform operational management practices in real-time on

540 agricultural land to help protect surface water from pollution, particularly from practices like

541 spreading manure without soil incorporation. As agricultural producers continue to adopt new

542 technologies and to use precision agriculture tools, short-term hydrologic forecasts can assist in

543 the effort to better manage agricultural land and reduce NPS pollution potential.

\section{6. Acknowledgements}

545 We would like to acknowledge high-performance computing support from Yellowstone 546 (http://n2t.net/ark:/85065/d7wd3xhc) provided by NCAR's Computational and Information 547 Systems Laboratory, funding support from the National Science Foundation Water Sustainability 548 and Climate under project number 1360415 and funding support from the USDA under project 549 number 2012-67019-19434

\section{$550 \quad$ References}

551 Abaza, M., Anctil, F., Fortin, V., Turcotte, R., 2014. Sequential streamflow assimilation for 552 short-term hydrological ensemble forecasting. J. Hydrol. 519, 2692-2706. 553 doi:10.1016/j.jhydrol.2014.08.038 
Arnold, J.G., Moriasi, D.N., Gassman, P.W., Abbaspour, K.C., White, M.J., Srinivasan, R., Santhi, C., Harmel, R.D., Van Griensven, A. VanLiew, M.W., Kannan, N., Jha, M.K., 2012. SWAT: Model Use, Calibration, and Validation. ASABE55, 1491-1508.

Arnold, J.G., Srinivasan, R., Muttiah, R.S., Williams, J.R., 1998. Large Area Hydrologic Modeling And Assessment Part I : Model Development J. Am. Assoc. Am. Water Resour. Assoc. 34, 73-89. doi:10.1111/j.1752-1688.1998.tb05961.x

Beven, K., 2001. How far can we go in distributed hydrological modelling? Hydrol. Earth Syst. Sci. 5, 1-12. doi:10.5194/hess-5-1-2001

Brooks, E.S., Saia, S.M., Boll, J., Wetzel, L., Easton, Z.M., Steenhuis, T.S., 2015. Assessing BMP Effectiveness and Guiding BMP Planning Using Process-Based Modeling. JAWRA J. Am. Water Resour. Assoc. n/a-n/a. doi:10.1111/1752-1688.12296

Collick, A.S., Fuka, D.R., Kleinman, P.J., Buda, A.R., Weld, J.L., White, M.J., Veith, T.L., Bryant, R.B., Bolster, C.H., Easton, Z.M., 2014. Predicting phosphorus dynamics in complex terrains using a variable source area hydrology model. Hydrol. Process. 601, 588-601. doi:10.1002/hyp.10178

Dahlke, H., Easton, Z.M., Fuka, D., Walter, M., Steenhuis, T.S., 2013. Real-time forecast of hydrologically sensitive areas in the Salmon Creek watershed, New York State, Using an Online Prediction Tool. Water 5, 917-944. doi:10.3390/w5030917

Dahlke, H.E., Easton, Z.M., Lyon, S.W., Todd Walter, M., Destouni, G., Steenhuis, T.S., 2012. Dissecting the variable source area concept - Subsurface flow pathways and water mixing processes in a hillslope. J. Hydrol. 420-421, 125-141. doi:10.1016/j.jhydrol.2011.11.052

Dunne, T., Leopold, L.B., 1978. Water in Environmental Planning. W. H. Freeman and Company, New York.

Dutta, D., Welsh, W.D., Vaze, J., Kim, S.S.H., Nicholls, D., 2012. A Comparative Evaluation of Short-Term Streamflow Forecasting Using Time Series Analysis and Rainfall-Runoff Models in eWater Source. Water Resour. Manag. 26, 4397-4415. doi:10.1007/s11269-012-0151-9

Easton, Z.M., Fuka, D.R., Walter, M., Cowan, D., Schneiderman, E., Steenhuis, T.S., 2008. Reconceptualizing the soil and water assessment tool (SWAT) model to predict runoff from variable source areas. J. Hydrol. 348, 279-291. doi:10.1016/j.jhydrol.2007.10.008

Easton, Z.M., Fuka, D.R., White, E.D., Collick, A.S., Biruk Ashagre, B., McCartney, M., Awulachew, S.B., Ahmed, a. a., Steenhuis, T.S., 2010. A multi basin SWAT model analysis of runoff and sedimentation in the Blue Nile, Ethiopia. Hydrol. Earth Syst. Sci. 14, 18271841. doi:10.5194/hess-14-1827-2010

Easton, Z.M., Walter, M.T., Fuka, D.R., White, E.D., Steenhuis, T.S., 2011. A simple concept for calibrating runoff thresholds in quasi-distributed variable source area watershed models. Hydrol. Process. 25, 3131-3143. doi:10.1002/hyp.8032

Fuka, D.R., Walter, M.T., Macalister, C., Degaetano, A.T., Steenhuis, T.S., Easton, Z.M., 2013. Using the Climate Forecast System Reanalysis as weather input data for watershed models. Hydrol. Process. 5623, 5613-5623. doi:10.1002/hyp.10073

Fuka, D.R., Walter, M.T., Macalister, C., Steenhuis, T.S., Easton, Z.M., 2014. SWATmodel: A multi-operating system, multi-platform SWAT model package in R. J. Am. Water Resour. Assoc. 50, 1349-1353. doi:10.1111/jawr.12170

Fuka, D.R., D. Auerbach, A.S. Collick, And Z.M. Easton. 2016. The TopoSWAT toolbox: Enhanced basin characterization in SWAT initializations. Environ. Model. Software. (In Review). 
Gassman, P.W., Reyes, M.R., Green, C.H., Arnold, J.G., 2007. The soil and water assessment tool: Historical development, applications, and future research directions. Trans. ASABE 50, 1211-1250. doi:10.1.1.88.6554

GFS, 2015. Global Forecast System (GFS) | National Centers for Environmental Information (NCEI) formerly known as National Climatic Data Center (NCDC) [WWW Document]. URL https://www.ncdc.noaa.gov/data-access/model-data/model-datasets/global-forcast-system-gfs (accessed 7.24.15).

Girvetz, E.H., Maurer, E., Duffy, P., Ruesch, A., Thrasher, B., Zganjar, C., 2013. Making Climate Data Relevant to Decision Making: The important details of Spatial and Temporal Downscaling 43.

Hanrahan, L.P., Jokela, W.E., Knapp, J.R., 2004. Dairy diet phosphorus and rainfall timing effects on runoff phosphorus from land-applied manure. J. Environ. Qual. 38, 212-217. doi:10.2134/jeq2007.0672

Hewlett, J.., Hibbert, A.R., n.d. Factors affecting the response of small watersheds to precipitation in humid regions. For. Hydrol. 275-290.

Homer, C.G., Dewitz, J.A., Yang, L., Jin, S., Danielson, P., Xian, G., Coulston, J., Herold, N.D., Wickham, J.D., Megown, K., 2015. Completion of the 2011 National Land Cover Database for the conterminous United States-Representing a decade of land cover change information. Photogramm. Eng. Remote Sensing 81, 345-354.

Horton, R.E., 1933. The role of infiltration in the hydrologic cycle, in: Transactions of the American Geophysics Union. pp. 446-460.

Hyndman, R.J., Khandakar, Y., 2008. Automatic time series forecasting: the forecast package for R Automatic time series forecasting : the forecast package for R. J. Stat. Softw. 27, 1-22.

IUSS, W.G.W., 2007. World Reference Base for Soil Resources 2006, first update 2007 (No. 103), World Soil Resources Reports. Rome.

Lyon, S.W., Seibert, J., Lembo, A.J., Walter, M.T., and Steenhuis T.S., 2006. Geostatistical investigation into the temporal evolution of spatial structure in a shallow water table. Hydrol. Earth Sys. Sci. Vol. 10 , pp. 113-125

Marjerison, R.D., Dahlke, H., Easton, Z.M., Seifert, S., Walter, M.T., 2011. A Phosphorus Index transport factor based on variable source area hydrology for New York State. J. Soil Water Conserv. 66, 149-157. doi:10.2489/jswc.66.3.149

Mohamoud, Y., 2004. Comparison of hydrologic responses at different watershed scales 1-81.

Moriasi, D., Arnold, J., Van Liew, M.W., Bingner, R.L., Harmel, R.D., Veith, T., 2007. Model evaluation guidelines for systematic quantification of accuracy in watershed simulations. Trans. ASABE 50, 885-900. doi:10.13031/2013.23153

NCEP, 2003. The GFS Atmospheric Model, Note 442. 14.

Needelman, B. A., Gburek, W.J., Petersen, G.W., Sharpley, A.N., Kleinman, P.J., 2004. Surface Runoff along Two Agricultural Hillslopes with Contrasting Soils. Soil Sci. Soc. Am. J. 68, 914. doi:10.2136/sssaj2004.0914

Page, T., Haygarth, P.M., Beven, K.J., Joynes, A., Butler, T., Keeler, C., Freer, J., Owens, P.N., Wood, G. a, 2005. Spatial variability of soil phosphorus in relation to the topographic index and critical source areas: sampling for assessing risk to water quality. J. Environ. Qual. 34, 2263-2277. doi:10.2134/jeq2004.0398

Pradhanang, S., Mukundan, R., Schneiderman, E.M., Zion, M., Anandhi, A., Pierson, D.C., Frei, A., Easton, Z.M., Fuka, D.R., and Steenhuis, T.S., 2013. Streamflow responses to projected 
climate change in New York City water supply watershed. J. Am Water Res. Assoc. 1-19. DOI: 10.1111/jawr.12086.

Puckett, L.J., 1995. Identifying the major sources of nutrient water pollution. Environ. Sci. Technol. 29, 408A-414A. doi:10.1021/es00009a001

Rutledge, G.K., Alpert, J. and Ebisuzaki, W., 2006. NOMADS: A climate and weather model archive at the National Oceanic and Atmospheric Administration. Bulletin of the American Meteorological Society, 87, 327-341

Schneiderman, E.M., Steenhuis, T.S., Thongs, D.J., Easton, Z.M., Zion, M.S., Neal, A.L., Mendoza, G.F., Walter, M.T., 2007. Incorporating variable source area hydrology into a curve-number-based watershed model. Hydrol. Process. 21, 3420-3430.

Sela, J., 1982. The NMC Spectral Model, , NOAA Technical Report NWS-30.

Sela, J., 1979. Spectral modeling at the National Meteorological Center. Mon. Weather Rev. 108, 1279-1292.

Shaman, J., M. Spiegelman, M. Cane and M. Stieglitz. 2006. A hydrologically driven model of swamp water mosquito population dynamics. Ecolog. Model. 194: 395-404.

Sharma, S.K., Mohanty, B.P., Zhu, J., 2006. Including Topography and Vegetation Attributes for Developing Pedotransfer Functions. Soil Sci. Soc. Am. J. 70, 1430. doi:10.2136/sssaj2005.0087

Shortle, J.S., Ribaudo, M., Horan, R.D., Blandford, D., 2012. Reforming agricultural nonpoint pollution policy in an increasingly budget-constrained environment. Environ. Sci. Technol. 46, 1316-1325. doi:10.1021/es2020499

Smith, D.R., Owens, P.R., Leytem, A. B., Warnemuende, E.A., 2007. Nutrient losses from manure and fertilizer applications as impacted by time to first runoff event. Environ. Pollut. 147, 131-137. doi:10.1016/j.envpol.2006.08.021

Sommerlot, A.R., Pouyan Nejadhashemi, A., Woznicki, S.A., Prohaska, M.D., 2013. Evaluating the impact of field-scale management strategies on sediment transport to the watershed outlet. J. Environ. Manage. 128, 735-748. doi:10.1016/j.jenvman.2013.06.019

Thompson, J.A., Pena-Yewtukhiw, E.M., Grove, J.H., 2006. Soil-landscape modeling across a physiographic region: Topographic patterns and model transportability. Geoderma 133, 5770. doi:10.1016/j.geoderma.2006.03.037

Tsai, M.J., Abrahart, R.J., Mount, N.J., Chang, F.J., 2014. Including spatial distribution in a datadriven rainfall-runoff model to improve reservoir inflow forecasting in Taiwan. Hydrol. Process. 28, 1055-1070. doi:10.1002/hyp.9559

Vadas, P.A., Jokela, W.E., Franklin, D.H., Endale, D.M., 2011. The effect of rain and runoff when assessing timing of manure application and dissolved phosphorus loss in runoff. J. Am. Water Resour. Assoc. 47, 877-886. doi:10.1111/j.1752-1688.2011.00561.x

Wagena, M.B. Sommerlot, A.R., Abiy, A.Z., Fuka, D.R., Collick, A.S., Langan, S., Easton Z.M., 2016. Regional climate change In the Blue Nile Basin: Implications for water resource availability and sediment transport. Climatic Change (doi: 10.1007/s10584-016-1785-z).

Walter, M.T., Walter, M.F., 1999. The New York City Watershed Agricultural Program (WAP): A model for comprehensive planning for water quality and agricultural economic viability. Water Resour. Impact 1, 5-8.

White, E.D., Easton, Z.M., Fuka, D.R., Collick, A.S., Adgo, E., McCartney, M., Awulachew, S.B., Selassie, Y.G., Steenhuis, T.S., 2011. Development and application of a physically based landscape water balance in the SWAT model. Hydrol. Process. 25, 915-925. doi:10.1002/hyp.7876 
690 Woodbury, J.D., Shoemaker, C.A., Easton, Z.M., Cowan, D.M., 2014. Application of SWAT 691 with and without Variable Source Area Hydrology to a Large Watershed. J. Am. Water 692 Resour. Assoc. 50, 42-56. doi:10.1111/jawr.12116

693 Wuertz, D., Miklovic, M., Boudt, C., Chausse, P. 2009. fGarch: Rmetrics - Autoregressive 694 Conditional Heteroskedastic Modelling.

695 Zambrano-Bigiarini, M., Rojas, R., 2013. A model-independent Particle Swarm Optimisation 696 software for model calibration. Environ. Model. Softw. 43, 5-25. 697 doi:10.1016/j.envsoft.2013.01.004 